\title{
Editorial
}

\section{PROGRAMAS DE FORMAÇÃO DE PESQUISADORES NA CIÊNCIA DA INFORMAÇÃO, NO BRASIL}

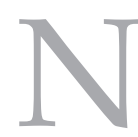

o Portal Capes na web, a página de Cursos Avaliados e Reconhecidos na área Comunicação e Informação contabiliza

83 Programas de Pós-Graduação, sendo 37 Mestrado/Doutorado, abrangendo cursos de Ciência da Informação (23), Comunicação (54) e Museologia (6). Dos 23 programas da Ciência da Informação, em quatro Regiões do Brasil, 11 oferecem cursos de mestrado e doutorado, com conceitos que variam entre 6 a 4 na avaliação quadrienal 2017. São três Programas na Região Sudeste, sendo dois em Minas Gerais, um no Centro-Oeste e dois na Região Sul.

No presente editorial resumimos as informações sobre os Programas de PósGraduação com conceitos 6 (UNESP) e 5 (UFMG, UnB, UFRGS e UFSC), de modo a descrever um painel das áreas de concentração, eixos temáticos e linhas de pesquisa oferecidas a pesquisadores em formação na área de Ciência da Informação. As informações foram coletadas nos páginas dos Programas na web.

\section{UNESP}

O PPGCI tem como área de concentração Informação, Tecnologia e Conhecimento está alicerçada em três Linhas de Pesquisa: Informação e Tecnologia, Produção e Organização da Informação e Gestão, Mediação e Uso da Informação. As linhas de pesquisa delineam de um conjunto de temáticas que se encontram espelhadas nas pesquisas dos docentes, nas disciplinas oferecidas, na produção científica e, por conseguinte, nas pesquisas discentes. Os eixos temáticos têm sido constantemente discutidos em sua coerência intrínseca, relativamente à abrangência almejada pela área de concentração e tendo em vista os elementos contextuais do Programa.

\section{UFMG}

O PPGCI tem como área de concentração Informação, Mediação e Cultura e se estrutura em três Linhas de Pesquisa: Memória social, patrimônio e produção do conhecimento, com ênfase nos aspectos construídos coletivamente, na sedimentação promovida pela memória social; Políticas públicas e organização da informação, enfatizando os aspectos institucionais relacionados com os ciclos de políticas públicas arquivísticas e informacionais; e Usuários, gestão do conhecimento e práticas informacionais, destacando o reconhecimento do caráter ativo dos sujeitos no uso e apropriação dos recursos informacionais.

\section{UFMG}

O PPG-GOC se fundamenta na conjunção entre três objetos de investigação na Ciência da Informação: conhecimento, tecnologia e pessoas. A sua área de concentração é Representação do conhecimento e suas Linhas de Pesquisa são: Arquitetura \& Organização do Conhecimento, 
que abrange perspectivas com ênfase primária nas questões que envolvem da organização do conhecimento em contextos diversos; Gestão $\mathcal{E}$ Tecnologia, com ênfase primária nos problemas que envolvem a organização, recuperação, e disseminação da informação e do conhecimento sob o ponto de vista da gestão de cada etapa em um contexto tecnológico.

\section{UnB}

O PPGCInf tem como área de concentração Gestão da Informação e busca, na Linha de Pesquisa Organização da Informação, propor conhecimentos nos níveis epistemológico, científico e prático relativos à origem, coleta, organização, estocagem, recuperação, interpretação, transmissão, transformação e uso da informação. A Linha de Pesquisa Comunicação e Mediação da Informação reúne estudos que buscam conhecimentos nos níveis epistemológico, científico e prático sobre processos de comunicação em diversos contextos e setores da sociedade.

\section{UFSC}

O PGCIN tem como área de concentração Gestão da informação, com ênfase no estudo dos fenômenos relacionados aos processos centrais da gestão da informação, São duas Linhas de Pesquisa: Organização, Representação e mediação da Informação e do Conhecimento, dividida nos eixos temáticos Organização e preservação do conhecimento e Profissionais da informação, competência em informação e publicação científica; e Informação, Gestão e Tecnologia, dividida nos eixos temáticos Informação e tecnologia e Gestão da Informação e do conhecimento.

\section{UFRGS}

O PPGCOM está estruturado em quatro linhas de Pesquisa: Informação, Redes sociais e tecnologias, com estudos teóricos e metodológicos aplicados à compreensão de fenômenos sociais mediados pelas tecnologias; Jornalismo e processos editoriais, com pesquisas em várias abordagens; Cultura e significação, com abordagens teóricas e metodológicas nas perspectivas dos imaginários, dos estudos culturais e das semióticas; e Mediações $e$ representações culturais e políticas, abordando processos de mediação e de representação nos campos da comunicação, da informação e de suas interfaces com a cultura e a política.

Outros seis Programas com Mestrado e Doutorado se dividem entre as Regiões Nordeste e Sudeste, nas Universidades Federais da Bahia, Paraíba e Pernambuco, na Universidade de São Paulo e no convênio entre a Universidade Federal do Rio de Janeiro e o Instituto Brasileiro de Informação em Ciência e Tecnologia.

Estes e os demais 12 Cursos que compõem esse campo constituem os espaços institucionais de formação de pesquisadores em Ciência da Informação, conforme Cursos Recomendados da Capes na área de Comunicação $e$ Informação. Este é o campo científico onde atuamos, onde preparamos novos pesquisadores.

Aos atores sociais que atuam nessas ações formativas, como docentes ou discentespesquisadores, nas diversas instituições que desenvolvem atividades de pós-graduação na Ciência da Informação, no Brasil, nossa homenagem e nosso agradecimento.

\section{Gustavo Henrique de Araújo Freire Isa Maria Freire Editores}

